\title{
ANÁLISE SENSORIAL DE HAMBÚRGUER BOVINO COM REDUZIDO TEOR DE SÓDIO
}

\author{
C.B.CARVALHO ${ }^{1}$, A.C. P.VITAL ${ }^{1}$, L. A. C.TONON ${ }^{2}$, G. G.PIERETTI ${ }^{1}$,G. \\ S.MADRONA ${ }^{2}$, I. N. do PRADO ${ }^{3}$ \\ ${ }^{1}$ Universidade Estadual de Maringá, Departamento de Ciências Agrárias \\ ${ }^{2}$ Universidade Estadual de Maringá, Departamento de Engenharia de Alimentos \\ ${ }^{3}$ Universidade Estadual de Maringá, Departamento de Zootecnia \\ Email para contato: grasiele@yahoo.com
}

\begin{abstract}
RESUMO - O consumo excessivo de sódio está diretamente relacionado ao desenvolvimento de doenças crônicas, como a hipertensão. Carnes e produtos cárneos representam importante contribuição para a ingestão de sódio na dieta. O objetivo deste estudo foi desenvolver e avaliar hambúrgueres bovinos com redução de 25 e $50 \%$ em seus teores de sódio. Foram formuladas três amostras de hambúrgueres e analisadas suas características sensoriais com 100 consumidores utilizando escala hedônica. A aceitabilidade dos hambúrgueres hipossódicos permaneceu acima de $70 \%$, no entanto, os consumidores apresentaram índices maiores de aceitabilidade global e detectaram menos a substituição de sódio por potássio para o tratamento com $25 \%$ de redução de sódio. O resultado da pesquisa de intenção de compra mostrou grande interesse do consumidor em adquirir o produto com $25 \%$ de redução de sódio, similar ao tratamento controle, portanto torna-se necessário avaliar aspectos de vida de prateleira dos hambúrgueres hipossódicos para tornar viável sua produção e comercialização.
\end{abstract}

\section{INTRODUÇÃO}

Uma das possíveis causas para o aumento da incidência de hipertensão arterial (HA) é o consumo de alimentos industrializados, enlatados, em conserva, defumados e temperos prontos, os quais quando consumidos em maior proporção, levam a ingestão de grande quantidade de sódio, muitas vezes maior do que o necessário para o organismo humano. (Pereira; Krieger, 2004).

O Ministério da Saúde pelo termo de compromisso número 004 de 2011 firmado em sete de abril de 2011 estabelece um acordo com a ABIA (Associação Brasileira das Indústrias de Alimentação) com a finalidade de definir metas nacionais para a redução do teor de sódio em alimentos processados no Brasil e coloca como uma das obrigações da indústria de alimentos avaliar a inclusão de novos alimentos com base em evidências científicas que justifiquem o impacto do consumo desta ingestão de sódio na população em geral e ou em grupos específicos (Ministério da Saúde, 2011).

De acordo com a Instrução Normativa No 20/MA/DIPOA de 31 de julho de 2000, se entende por Hambúrguer o produto cárneo industrializado obtido da carne moída dos animais de açougue, adicionado ou não de tecido adiposo e ingredientes, moldado e submetido a processo tecnológico adequado e segundo a Portaria $\mathrm{n}^{\circ} 27$, de 13 de janeiro de 1998 do SVS/MS - Ministério da Saúde. Secretaria de Vigilância Sanitária que determina a redução de 
25\% de sódio ou $120 \mathrm{mg}$ por $100 \mathrm{~g}$ do produto sólido para o produto ser considerado light em relação a composição de sódio.

Substituir o cloreto de sódio pelo sal de ervas é uma das maneiras mais promissoras para se controlar a hipertensão arterial (Alino et al., 2010).

O uso de sais substitutos como o cloreto de potássio é limitado principalmente pelo seu sabor amargo. Por isso, vários compostos inibidores ou mascaradores (extrato de levedura ou uma mistura de ervas naturais) do amargor têm sido propostos para serem adicionados aos produtos relacionados principalmente ao parâmetro sabor (Desmond, 2006).

A substituição parcial do cloreto de sódio pelo cloreto de potássio e a adição de ervas aromáticas e especiarias ao hambúrguer parece ser uma saída promissora para a redução de sódio e a manutenção da palatabilidade deste produto.

Neste contexto, este estudo teve como objetivo desenvolver hambúrguer bovino, utilizando tempero hipossódico, substituindo o cloreto de sódio por sal light em percentuais de 25 (F25) e 50\% (F50) utilizando ervas e especiarias.

\section{MATERIAIS E MÉTODOS}

\subsection{Amostras}

As amostras de hambúrguer Bovino (carne bovina+ proteína texturizada de soja+ especiarias e ervas + água gelada) foram produzidas no laboratório de carnes da Engenharia de Alimentos - UEM, embaladas em sacos de polietileno e mantidas em congelamento a $-18^{\circ}$ C de acordo com o fluxograma de elaboração dos hambúrgueres (Figura 1).

Os hambúrgueres foram moldados utilizando cortador manual pesando 80g/unidade e $1 \mathrm{~cm}$ de espessura. A proteína de soja texturizada foi hidratada com água fervente, após resfriada e retirado o excesso de água. A carne bovina utilizada foi a capa de contra filé, devido a seu mediano teor de gordura, a proteína de soja texturizada fina natural e as ervas e especiarias foram adquiridas no comércio local. Para a produção do hambúrguer foram seguidas as normas da Instrução Normativa No 20/MA/DIPOA. 


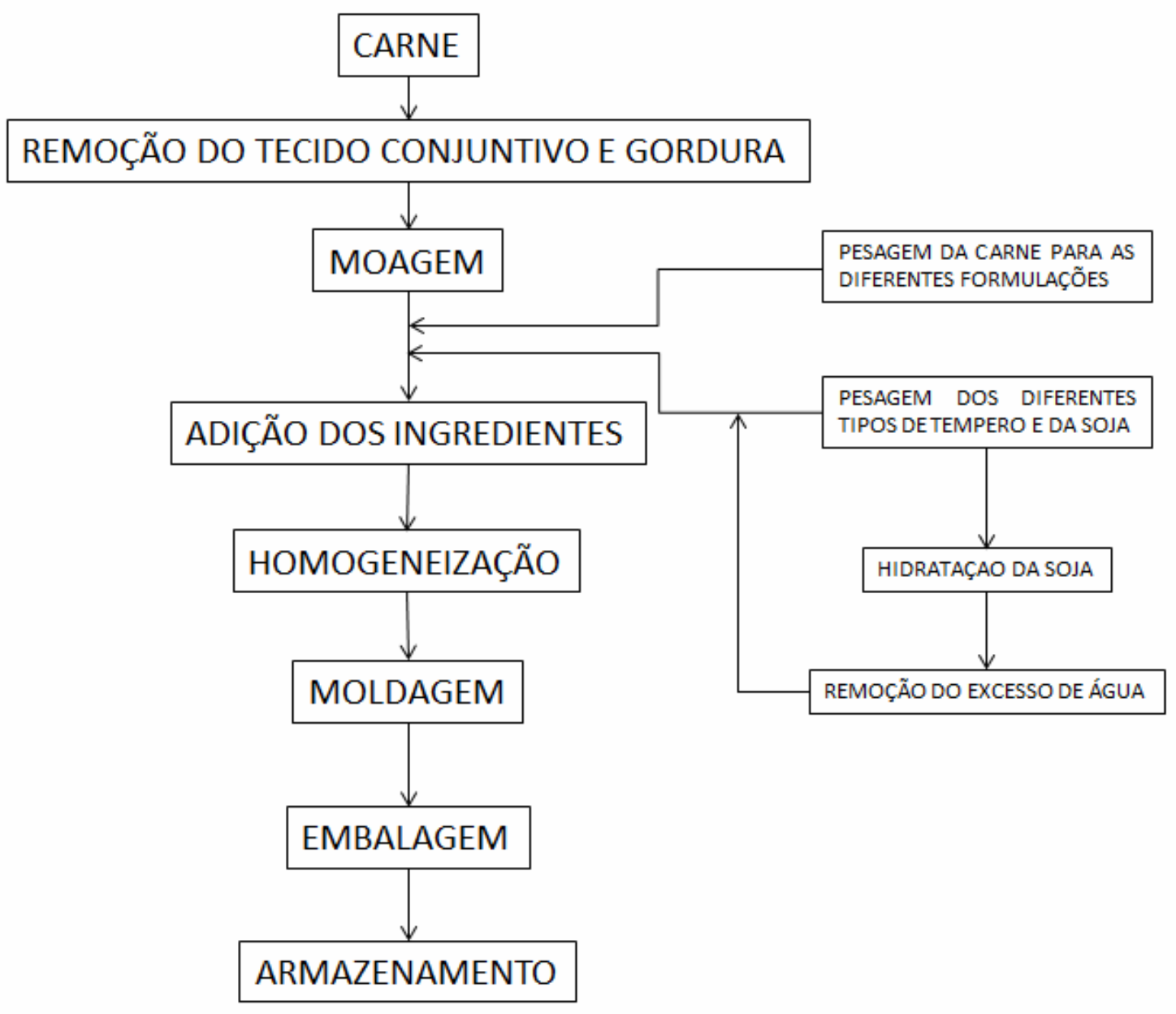

Figura 1-Fluxograma de elaboração dos hambúrgueres.

\subsection{Tratamento de amostras}

Foram realizados 3 tratamentos, tratamento controle- Especiarias e ervas + Cloreto de sódio (100\%), F25 - Especiarias e ervas + cloreto de sódio(50\%) + sal light (50\%),F50 Especiarias e ervas + sal light (100\%). A Tabela 1 apresenta as formulações.

Utilizou-se para a formulação do tempero produto hipossódico sal ligh marca Cisne com informação nutricional para porção de $1 \mathrm{~g}$ de $267 \mathrm{mg}$ de potássio, $191 \mathrm{mg}$ de sódio e $25 \mathrm{mcg}$ de iodo. O tratamento controle foi fabricado com sal comum marca Cisne e informação nutricional para $1 \mathrm{~g}$ de $390 \mathrm{mg}$ de sódio e $25 \mathrm{mcg}$ de iodo. Foram utilizados $2 \mathrm{~g}$ de tempero completo para cada $100 \mathrm{~g}$ de produto. 
Tabela 1 - Formulações com substituição de 25 e 50\% de sódio por potássio e adição de ervas e especiarias

\begin{tabular}{llll}
\hline \multirow{2}{*}{ Ingredientes (\%) } & \multicolumn{3}{c}{ Hambúrguer } \\
\cline { 2 - 4 } & CON & F25 & F50 \\
\hline Carne Bovina & 88.67 & 88.67 & 88.67 \\
PTS & 4 & 4 & 4 \\
Água gelada & 5 & 5 & 5 \\
NaCl & 2.0 & 1.5 & 1.0 \\
KCl & - & 0.5 & 1.0 \\
Allium sativum & 0.2 & 0.2 & 0.2 \\
Oreganumvulgare & 0.02 & 0.02 & 0.02 \\
Bixaorellana & 0.1 & 0.1 & 0.1 \\
Capsicum frutescens & 0.01 & 0.01 & 0.01 \\
\hline
\end{tabular}

\subsection{Análise sensorial}

Foi realizada com 100 consumidores não treinados na Universidade Estadual de Maringá (UEM). Verificou-se a aceitabilidade das amostras preparadas de Hambúrguer bovino, grelhados, cortados no tamanho $2 \times 2 \mathrm{~cm}$ e servidos imediatamente após o preparo à temperatura de $60^{\circ} \mathrm{C}$.

O produto foi avaliado em relação aos atributos sabor, odor, textura e aceitação global. Para essa avaliação foi utilizada escala hedônica estruturada de 9 pontos $(9=$ gostei muitíssimo; 1=desgostei muitíssimo) (Monteiro, 2005). Avaliou-se também a intenção de compra dos produtos com escala de 3 pontos (certamente não compraria, talvez comprasse/talvez não comprasse e certamente compraria).

\subsection{Análises Estatísticas}

O delineamento experimental utilizado foi inteiramente casualizado. Os dados coletados foram submetidos à análise de variância, utilizando programa estatístico SAS 9.0. Comparação entre as médias feita através do teste Tukey a 5\% de probabilidade.

\section{RESULTADOS E DISCUSSÕES}

\subsection{Análises sensoriais}

Conforme apresentado na Tabela 2 não foram observadas diferenças significativas para o atributo textura para os três níveis de substituição, assim como observado por Carraro et al., 2012, a adição de ervas e a redução do $\mathrm{NaCl}$ não alterou a textura de mortadelas. No mesmo estudo não foram encontradas diferenças relacionas ao sabor.

Kamleh et al. (2012) não observaram diferenças em relação a nenhum dos atributos sensoriais avaliados em queijos referentes a substituição de $\mathrm{NaCl}$ por $\mathrm{KCl}$, já neste trabalho, em relação aos outros atributos, como aroma, a amostra controle obteve a maior nota, sendo diferente das outras duas formulações. 
Em relação ao sabor, não houve diferença entre a amostra controle e F2, ou seja, o $\mathrm{KCl}$ nesta proporção não influenciou a percepção dos provadores. Resultados semelhantes são observados em estudo realizado por Vogel et al. (2011) onde em relação ao sabor de salsichas, pode-se verificar que as formulações com sal comum e com substituição de $25 \%$ de $\mathrm{NaCl}$ por $\mathrm{KCl}$ não apresentaram diferença, sendo significativa apenas para substituições acima de $50 \%$ e assim como neste estudo em relação a avaliação global, observou-se que não houve diferença entre as amostras substituídas de 25 e $50 \%$ em relação ao padrão.

As notas para todos os atributos no presente estudo ficaram acima de 6,7, entre gostei ligeiramente e gostei muito, o índice de aceitação das amostras ficou acima de $70 \%$, mostrando uma boa aceitação do produto.

Tabela 2 - Valores das médias da análise sensorial de hambúrguer de carne bovina, submetido a diferentes níveis de substituição de cloreto de sódio por cloreto de potássio.

\begin{tabular}{lllllll}
\hline Amostra & Aroma & Sabor & Textura & Avaliação global & $\begin{array}{l}\text { Índice de } \\
\text { aceitação }\end{array}$ & $\begin{array}{l}\text { Intenção de } \\
\text { compra }\end{array}$ \\
\hline Controle & $7,40 \pm 1,26^{\mathrm{a}}$ & $7,35 \pm 1,38^{\mathrm{a}}$ & $6,86 \pm 1,56^{\mathrm{a}}$ & $7,26 \pm 1,19^{\mathrm{a}}$ & $80,66 \%$ & $2,51 \pm 0,59^{\mathrm{a}}$ \\
F25 & $6,96 \pm 1,33^{\mathrm{b}}$ & $7,20 \pm 1,25^{\mathrm{a}}$ & $6,86 \pm 1,56^{\mathrm{a}}$ & $7,08 \pm 1,11^{\mathrm{a}}$ & $78,66 \%$ & $2,36 \pm 0,57^{\mathrm{a}}$ \\
F50 & $6,82 \pm 1,44^{\mathrm{b}}$ & $6,78 \pm 1,49^{\mathrm{b}}$ & $7,09 \pm 1,61^{\mathrm{a}}$ & $6,92 \pm 1,48^{\mathrm{a}}$ & $76,88 \%$ & $2,13 \pm 0,76^{\mathrm{b}}$ \\
\hline
\end{tabular}

Médias seguidas de letras iguais, na mesma coluna, não diferem entre si pelo Teste de Tukey a 5\% de significância $(p<0,05)$.

\subsection{Intenção de compra}

Foi avaliada a intenção de compra dos provadores em relação ao hambúrguer com redução de sódio juntamente com a análise sensorial. Verificou-se que a maioria dos provadores certamente e provavelmente comprariam os hambúrgueres, apenas um pequeno percentual dos provadores, certamente não comprariam os produtos como mostra a Figura 2.

Assim, os resultados apresentados na análise sensorial, indicam boa aceitação ao produto, associados com os resultados obtidos na intenção de compra demonstram que o produto pode ser mais uma opção no mercado, não apenas para aqueles que precisam de uma dieta restritiva em relação ao sódio, mas também para aqueles consumidores que se preocupam com a prevenção de doenças associadas ao consumo excessivo de sódio.

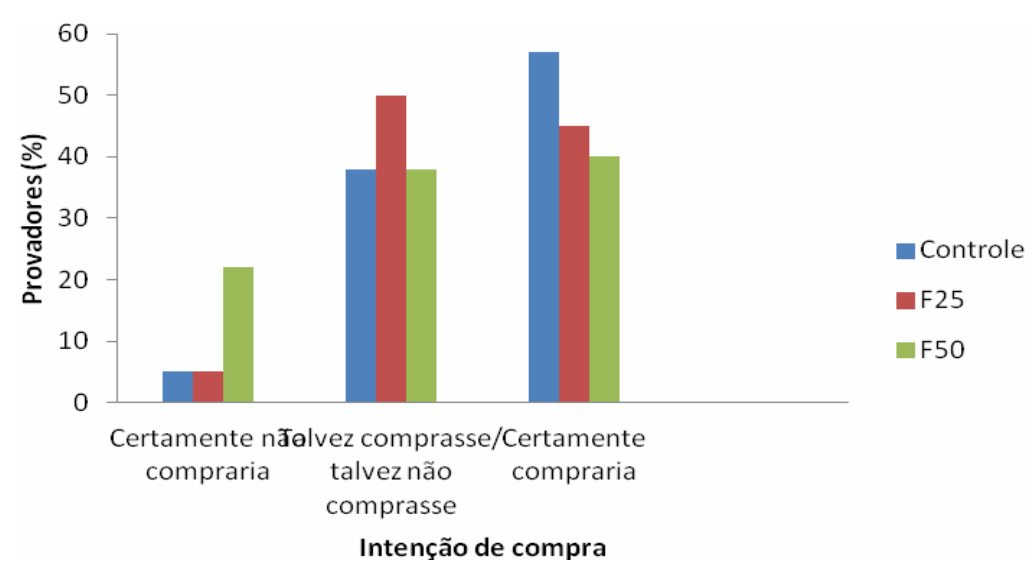

Figura 2 - Intenção de compra de hambúrguer com redução de sódio. Controle - $100 \% \mathrm{NaCl}$; F25 - Substituição de $25 \%$ de $\mathrm{NaCl}$ por sal light; F50 - Substituição de $50 \%$ de $\mathrm{NaCl}$ por sal light. 


\section{CONCLUSÃO}

A substituição de cloreto de sódio por sal light no produto hambúrguer bovino com a utilização de ervas e especiarias mostrou-se uma estratégia eficaz para viabilizar a aceitabilidade deste produto, não alterando sua qualidade sensorial ao nível de $25 \%$ de substituição e possibilitando assim a redução de seus teores de sódio, mantendo as características de um produto mais saudável e sensorialmente aceito pelo consumidor.

\section{REFERÊNCIAS}

ALIÑO, M, GRAU, R; TOLDRÁ, F; BARAT, JM. Phisicochemical changes in drycured hams salted with potassium, calcium and magnesium chloride as a partial replacement for sodium chloride. Meat Sci. 86, p.331-336, 2010.

CARRARO, C.I.; MACHADO, R.; ESPINDOLA, V.; CAMPAGNOL, P. C. B.; POLLONIO, M. A. R.The effect of sodium reduction and the use of herbs and spices on the quality and safety of Bologna sausage.Cienc.Tecnol.Aliment., Campinas, v. 32, n. 2, p.289295, 2012.

DESMOND, E.Reducing salt: A challenge for the meat industry. Meat Sci.v.74, p.188196, 2006.

INSTRUÇÃO NORMATIVA No 20, de 31 de Julho de 2000. Aprova o regulamento técnico de identidade e qualidade de hambúrguer. D.O.U. - Diário Oficial da União; Poder Executivo, de 20 de novembro de 2001. MA/DIPOA - Ministério da Agricultura. Departamento de Inspeção de Produtos de Origem Animal.

KAMLEH, R.; OLABI, A.; TOUFEILI, I.; NAJM, N. E. O.; YOUNIS, T.; AJIB, R. The effect of substitution of sodium chloride with potassium chloride on the physicochemical, microbiological, and sensory properties of Halloumi cheese.Journal of Dairy Science, v.95, n.3, p. 1140-1151, 2012.

MINISTÉRIO DA SAÚDE,Termo de compromisso $\mathbf{N}^{\circ}$ 4/2011. Disponível em <http://www.saude.gov.br> acesso em 08/04/2011.

MONTEIRO, A.R.G.Introdução à análise sensorial de alimentos.Coleção Fundamentum número 21.EDUEM:Maringá, p.27-41,2005.

PEREIRA, A. da C.; KRIEGER, J. E. Sal, hipertensão e genética. Rev. da Socied. Bras. Hipert., Rio de Janeiro, v.7, n.2, p. 61-64, 2004.

VOGEL, C. C.; PAZUCH, C. M.; SARMENTO, C. M. P.; BACK, L.; SECCO, T. H. Development of sausage with reduced sodium (salt light). ver. Ciênc. Exa. Nat., v. 13, n. 3, p. 305-316, 2011. 